\title{
Heparin coating in biodegradable ureteral stents does not decrease bacterial colonization-assessment in ureteral stricture endourological treatment in animal model
}

\author{
Federico Soria $^{1}$ ^, Julia E. de La Cruz ${ }^{1}$, Tomás Fernandez ${ }^{2}$, Alberto Budia ${ }^{3}$, Álvaro Serrano ${ }^{4}$, \\ Francisco M. Sanchez-Margallo ${ }^{5}$
}

${ }^{1}$ Endourology Department, Jesús Usón Minimally Invasive Surgery Centre Foundation, Cáceres, Spain; ${ }^{2}$ Urology Department, University Hospital Morales Meseguer, Murcia, Spain; ${ }^{3}$ Urology Department, University Hospital La Fe, Valencia, Spain; ${ }^{4}$ Urology Department, University Hospital Clínico San Carlos, Madrid, Spain; J Jesús Usón Minimally Invasive Surgery Centre, Cáceres, Spain

Contributions: (I) Conception and design: F Soria; (II) Administrative support: F Soria; (III) Provision of study materials or patients: F Soria, JE de La Cruz; (IV) Collection and assembly of data: F Soria, JE de La Cruz; (V) Data analysis and interpretation: F Soria, JE de La Cruz, T Fernández, A Budia, A Serrano; (VI) Manuscript writing: All authors; (VII) Final approval of manuscript: All authors.

Correspondence to: Dr. Federico Soria. Endourology-Endoscopy Coordinator, Jesus Uson Minimally Invasive Surgery Centre Foundation, Carretera N-521, Km. 41.8. C.P.10071, Cáceres, Spain. Email: fsoria@ccmijesususon.com.

Background: We assessed an antireflux biodegradable heparin-coated ureteral stent (BraidStent $\left.{ }^{\circledR}-\mathrm{H}\right)$ in an animal model comparative study after endoscopic treatment of ureteral strictures.

Methods: A total of 24 female pigs underwent initial endoscopic, nephrosonographic, and contrast fluoroscopy assessment of the urinary tract. Afterward, unilateral laparoscopic ureteral stricture model was performed. Three weeks later, the animals underwent laser endoureterotomy and were randomly assigned to Group-I, in which a double-pigtail stent was placed for 6 weeks, or Group-II, in which a BraidStent ${ }^{\circledR}-\mathrm{H}$ was placed. Follow-up was carried out by ultrasonography, contrast fluoroscopy, ureteroscopy, urinalysis and bacteriuria assessment at 3, 6, 12 and 5 months. Finally, a pathological study of the urinary system was performed.

Results: There were no animals in Group-II with vesicoureteral reflux, with significance at 6 weeks with Group-I. Distal ureteral peristalsis was maintained in $50-75 \%$ in Group-II at 1-6 weeks. The $91.7 \%$ of stents in Group-II were degraded between 3-6 weeks, without obstructive fragments. Bacteriuria in Group II was $33.3-50 \%$ at 3 and 6 weeks. The global success rate by groups was $91.6 \%$ and $87.5 \%$ in groups I and II, respectively, with no statistical significance.

Conclusions: BraidStent ${ }^{\circledR}-\mathrm{H}$ has been shown to be as efficacious as current ureteral stents in the treatment of benign ureteral strictures following laser endoureterotomy. In addition, it reduces the morbidity associated with current stents and has a homogeneous and predictable degradation rate of about 6 weeks, with no obstructive fragments. Future studies are required to improve the antibacterial coating to reduce BraidStent ${ }^{\circledR}-\mathrm{H}$ contamination in view of the results obtained with the heparin coating.

Keywords: Biodegradable ureteral stent; ureteral stricture (US); heparin coated; endoureterotomy; ureteral sent

Submitted Jan 10, 2021. Accepted for publication Mar 02, 2021.

doi: $10.21037 / \mathrm{tau}-21-19$

View this article at: http://dx.doi.org/10.21037/tau-21-19

^ ORCID: 0000-0002-1895-1280. 


\section{Introduction}

The management of ureteral strictures (US) still represents a great therapeutic challenge today (1). Open or laparoscopic surgery remains the gold standard for the treatment of US, especially in severe cases and long strictures $(2,3)$. However, due to the extensive introduction of endourologic techniques, laser endoureterotomy has proven to be the treatment of choice in well-selected patients with benign and short US, principally because it is associated with excellent tissue cutting and clotting ability, low cost, by reducing the need for hospital stay, low morbidity, and favourable results, and because it is a safe treatment $(1,3,4)$.

There is broad consensus on the necessity for placement of a post-endoureterotomy ureteral stent (1,3). Even so, some research groups have recently evaluated biodegradable ureteral stents (BUS), because of the high morbidity associated with ureteral stents. Over $80 \%$ of patients experienced stent related pain affecting daily activities, $32 \%$ reported sexual dysfunction, and 58\% showed reduced work capacity, as well as the necessity of retrieval them (5-8). BraidStent ${ }^{\circledR}$ is a BUS which has previously demonstrated great ability to degrade in the urinary tract in a controlled and predictable fashion in animal model. However, this new stent has been related to a high rate of bacterial contamination, with values up to $50 \%$ of affected study subjects (8).

Therefore, the aim of this animal model comparative study is to assess the efficacy of the new BraidStent- $\mathrm{H}^{\circledR}$ after laser endoureterotomy for the treatment of benign and intrinsic USs. This ureteral stent has a heparin coating, as this glycosaminoglycan has previously proven its ability to avoid bacterial adhesion to ureteral stents $(9,10)$. Moreover, the new design is a strictly intraureteral stent; its purpose is to obviate the main causes of morbidity associated with current ureteral stents, i.e., vesicoureteral reflux (VUR) and lower urinary tract symptoms (LUTS), related to the vesical end of the stents (11). We present the following article in accordance with the ARRIVE reporting checklist (available at http://dx.doi.org/10.21037/tau-21-19).

\section{Methods}

Twenty-four healthy female pigs (Large White spp) were used in this study. Pigs were housed in individual housing. The porcine model is used in translational studies focused on endourology because of its anatomical, physiological and histological similarities to humans (7). Experiments were performed under a project license (NO.: 003/13) granted by Jesus Uson Minimally Invasive Surgery Centre's Ethical Committee for Animal Research, in compliance with The Institutional Animal Care and Use Committee European Union (Directive 2010/63/EU on the protection of animals used for scientific purposes).

\section{Ureteral stricture animal model. Endoureterotomy and stenting.}

After endotracheal intubation and general anesthesia with Isofluorane, a hematologic, blood biochemistry, urinalysis and bacteriuria analysis were performed. Bacteriuria was considered positive when the urine was $>10^{5} \mathrm{CFU} / \mathrm{mL}$. All study animals were administered a prophylactic antibiotic treatment on the day before and two days after each study phase (Enrofloxacin IM, $2 \mathrm{mg} / \mathrm{kg} \mathrm{q} 24 \mathrm{~h}$ ). Buprenorhine IM (0.01 mg/kg q $12 \mathrm{~h}$ ) and Ketorolac IM (1 mg/kg q 12 h) were used as analgesia after surgery.

Next, a nephrosonographic study was performed; this makes it possible to assess and grade pyelocalyceal dilatation, according to SFU (Society for Fetal Urology) classification (12). Later on, assessment and cystoscopic classification of the urothelium at the ureteral orifice and bladder trigone were performed by means of the validated "UOScore" $\left(\mathrm{UO}_{0}\right.$ to $\mathrm{UO}_{3}$, the higher the score, the greater the injury) (8). Simulated voiding cystourethrography (SVCUG) was carried out to evaluate VUR at baseline, at 3, 6, and 12 weeks after ureteral stenting, as well as a final follow-up at 5 months (8). Excretory urography was performed to assess upper urinary tract morphology and to measure ureteral peristalsis (waves/min). Finally, retrograde ureteropyelography, which permits internal ureteral diameter measurement using digital fluoroscopy software.

The proximal ureter was partially closed by means of a short-term biodegradable ligature in the same surgical procedure and through laparoscopy approach, achieving the unilateral ureteral stricture model $(8,13)$. Three weeks later, the US was diagnosed, followed by its treatment by Holmium laser retrograde endoureterotomy $(1.2 \mathrm{~J} /$ pulse- $10 \mathrm{~Hz})$.

Then, the 24 study animals underwent simple randomization divided into two homogeneous groups, depending on the ureteral stent. A 5Fr polymeric ureteral double pigtail stent was placed in Group-I (Control group) for a 6-week period (Universa ${ }^{\circledR}$ Soft, $22 \mathrm{~cm}$, Cook ${ }^{\circledR}$ Medical). A new antireflux, biodegradable and heparin covered stent (BraidSten $\left.{ }^{\circledR}-\mathrm{H}\right)$ was placed in a retrograde fashion in Group-II by sliding over a guidewire. BraidStent ${ }^{\circledR}-\mathrm{H}$ is 


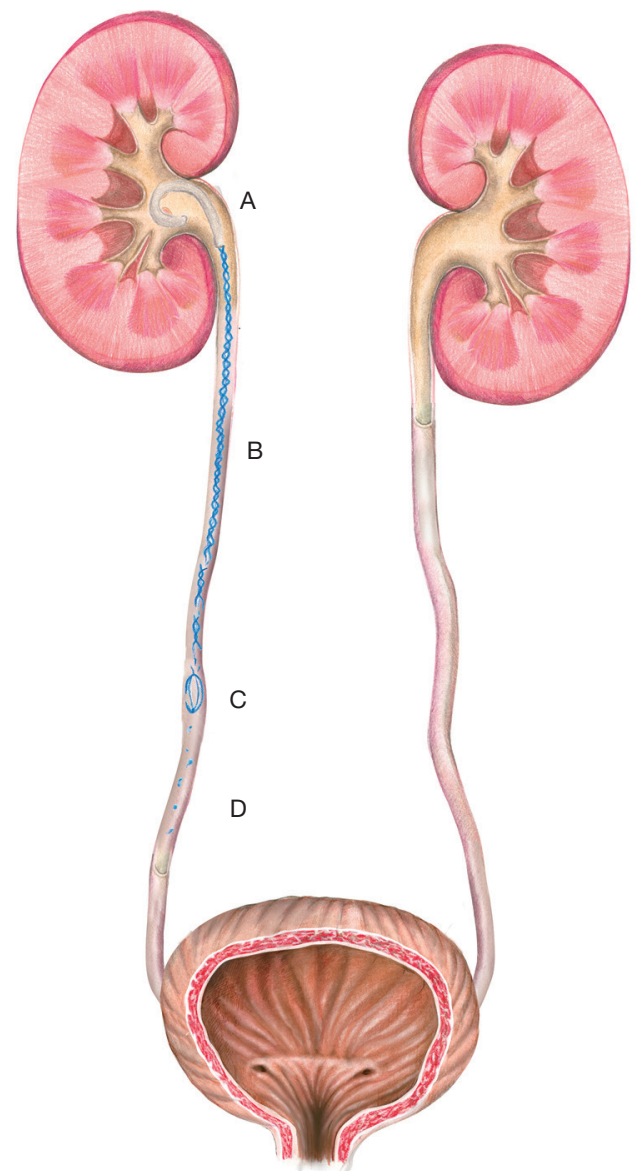

Figure 1 Illustration of the BraidStent ${ }^{\circledR}-\mathrm{H}$ in upper urinary tract. (A) Proximal pigtail. (B) Central section with a four-thread braided section. (C) Distal anchoring system with a rounded-edge fourthread basket. (D) Small degradation fragments. a strictly intraureteral stent designed as follows: a pigtail proximal end; a 9-cm-long central section with a four-thread braided section, $3 \mathrm{Fr}$ in diameter; and finally, a distal ureteral anchoring system with a rounded-edge four-thread basket that measures $2 \mathrm{~cm}$ in length; 36Fr when expanded. Two biocompatible and biodegradable copolymers with different degradation rates were used: co-polymer $\mathrm{A}$, slow rate and polymer $\mathrm{B}$ fast degradation rate. This feature allows the stent to remain in place for about 6 weeks. The BraidStent ${ }^{\circledR}-\mathrm{H}$ was designed to avoid passing through the ureterovesical junction (UVJ) to prevent bladder trigone irritation and VUR. (Figure 1). The heparin coating of the BraidStent ${ }^{\circledR}-\mathrm{H}$ was carried out using the dip coating technique (14). The stents were completely immersed in sodium heparin with a concentration of $5,000 \mathrm{UI} / \mathrm{mL}$ and then dried in an oven at $60{ }^{\circ} \mathrm{C}$ for two hours. After this process, each BraidStent ${ }^{\circledR}-\mathrm{H}$ had $233 \mathrm{mg}(72 \mu \mathrm{m})$ of heparin coating. In our previous in vitro studies, we were able to determine the release over time of heparin by the BraidStent ${ }^{\circledR}-\mathrm{H}$. To this end, fifteen BraidStent ${ }^{\circledR}-\mathrm{H}$ were incubated in artificial urine, at $37^{\circ} \mathrm{C}$ and $60 \mathrm{rpm}$ orbital agitation. The BraidStent ${ }^{\circledR}-\mathrm{H}$ were coated with a layer of $72 \mu \mathrm{m}$ of sodium heparin $5,000 \mathrm{UI} / \mathrm{mL}$. Urine sampling and exchanges were performed in the followups at $0,3,6,12,24,48,72$, and 96 hours. The presence and concentration of heparin were analysed by means of an ELISA kit: Human Heparin Sodium (HS) ELISA kit MBS3802043 MyBioSource ${ }^{\circledR}$. The results regarding the average concentrations at the different follow-ups are shown in the Figure 2. The heparin coating of the BraidStent ${ }^{\circledR}-\mathrm{H}$ starts its release at the beginning of the contact with the urine

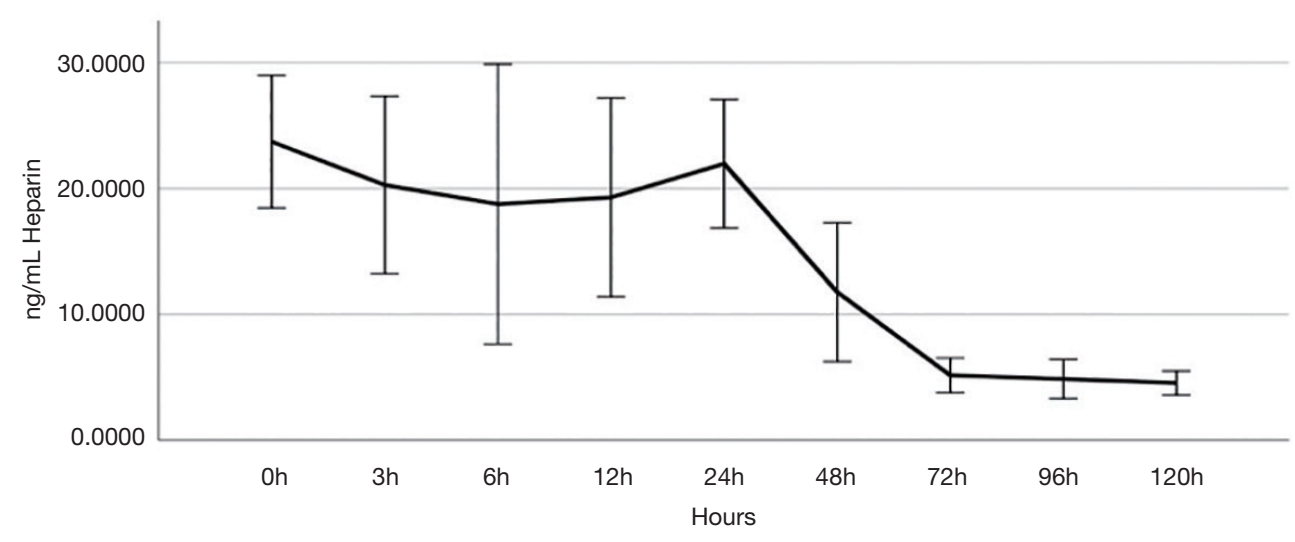

Figure 2 Concentration of heparin released in vitro determined by ELISA test. 
and is released mainly in the first 72 hours.

\section{Follow-up}

Follow-ups were done at 3, 6, and 12 weeks, using the previously described diagnostic procedures. In order to closely assess the degradation rate, the size of degradation fragments and the loss of mechanical properties of the BraidStent ${ }^{\circledR}-\mathrm{H}$, intermediate follow-ups at 4 and 5 weeks by ureteroscopy and contrast fluoroscopy were carried out exclusively in Group-II. Ureteroscopic evaluation was carried out by intermittent irrigation with normal saline solution through the $\mathrm{Cook}^{\circledR}$ Medical irrigation system (Table 1).

\section{End-study evaluation. Imaging and pathological assessment}

The final follow-up was performed at 5 months by means of ultrasonography, cystoscopy, ureteroscopy, and contrast fluoroscopy. The experimental study was finished by removing the urinary tract en bloc for pathological study. Histological slices were obtained from endoureterotomy site, ureteral segment where distal end of BraidStent ${ }^{\circledR}-\mathrm{H}$ was placed, and ureteral orifices/bladder trigone. A validated healing score was used; $0-3$; the higher the score the greater the histological damage to the ureteral or bladder wall (Table 2) $(8,13)$.

Global success rate was strictly defined as the following: relief of signs and ultrasound and fluoroscopic resolution of US and obstructive uropathy at the end of the study.

\section{Statistical analysis}

To determine the sample size, a hypothesis contrast was implemented (the means were compared); a total of twelve animals per group were obtained (0.05 level of significance; $90 \%$ statistical power). Quantitative variables are expressed as mean \pm standard deviation, and the normality study of these variables is carried out using the Shapiro-Wilks test. Variables that fit a normal distribution are compared using the Student T-test for independent samples, while hypothesis testing between non-parametric variables is performed using the Mann-Whitney U-test. The evolution of quantitative variables throughout the phases of the study is evaluated by means of the ANOVA with repeated measurements. Categorical variables are expressed as percentages and their comparison between groups is made by means of the Chi-square test or the Fisher exact test. The relationship of the categorical variables between phases is analysed using the McNemar test.

\section{Results}

None of the study animals showed morphologic abnormalities in the urinary tract, VUR, or asymptomatic bacteriuria at baseline study. No significant alterations in urinary $\mathrm{pH}$ were found throughout the different phases of the study (Table 1). Three weeks after creation of the obstructive uropathy model, all the animals revealed US on ultrasonographic and fluoroscopic examination. All strictures treated were $\leq 10 \mathrm{~mm}$ in length. Laser endoureterotomy was performed without complications in all animals until periureteral fat was visualised, and the procedure was checked by extravasation of contrast medium. No complications occurred during stent placement in any of the groups (Table 1).

\section{3-week follow-up}

We found a small retroperitoneal urine collection under ultrasound assessment in one animal per group; these were not treated. No extravasation of contrast medium was revealed by retrograde ureteropyelography in any of the cases. All subjects in Group-II showed non-obstructive urothelial hyperplastic growth where the BraidStent ${ }^{\circledR}-\mathrm{H}$ distal tip was placed. None of the BUS showed macroscopic degradation signs. An asymptomatic bacteriuria rate of $25 \%$ and $33.3 \%$ was found in Groups I and II, respectively, with no statistical significance. Significance was actually found in the assessment of distal ureteral peristalsis, since up to $50 \%$ of animals in Group-II maintained it, whereas no animals in Group-I (Figure 3).

\section{4- and 5-week follow-ups}

Follow-up at 4 weeks through ureteroscopy and fluoroscopy showed that polymer-B had started to degrade, whereas copolymer-A was intact. The ureter remained straight and dilated. No polymer-B was demonstrated in the structure of $83 \%$ of BUS at 5 weeks. Copolymer-A had only started fragmentation of the distal anti-migration system in $58 \%$ of stents; this system is exclusively designed by this copolymer-A. BraidStent ${ }^{\circledR}-\mathrm{H}$ retained its integrity and structure despite the absence of polymer-B. No obstructive degradation fragments were observed at the ureteral level at any of the follow-ups, although vesical urine was cloudy and contained tiny suspended fragments (Figures 4 and 5). 
Table 1 Results summary

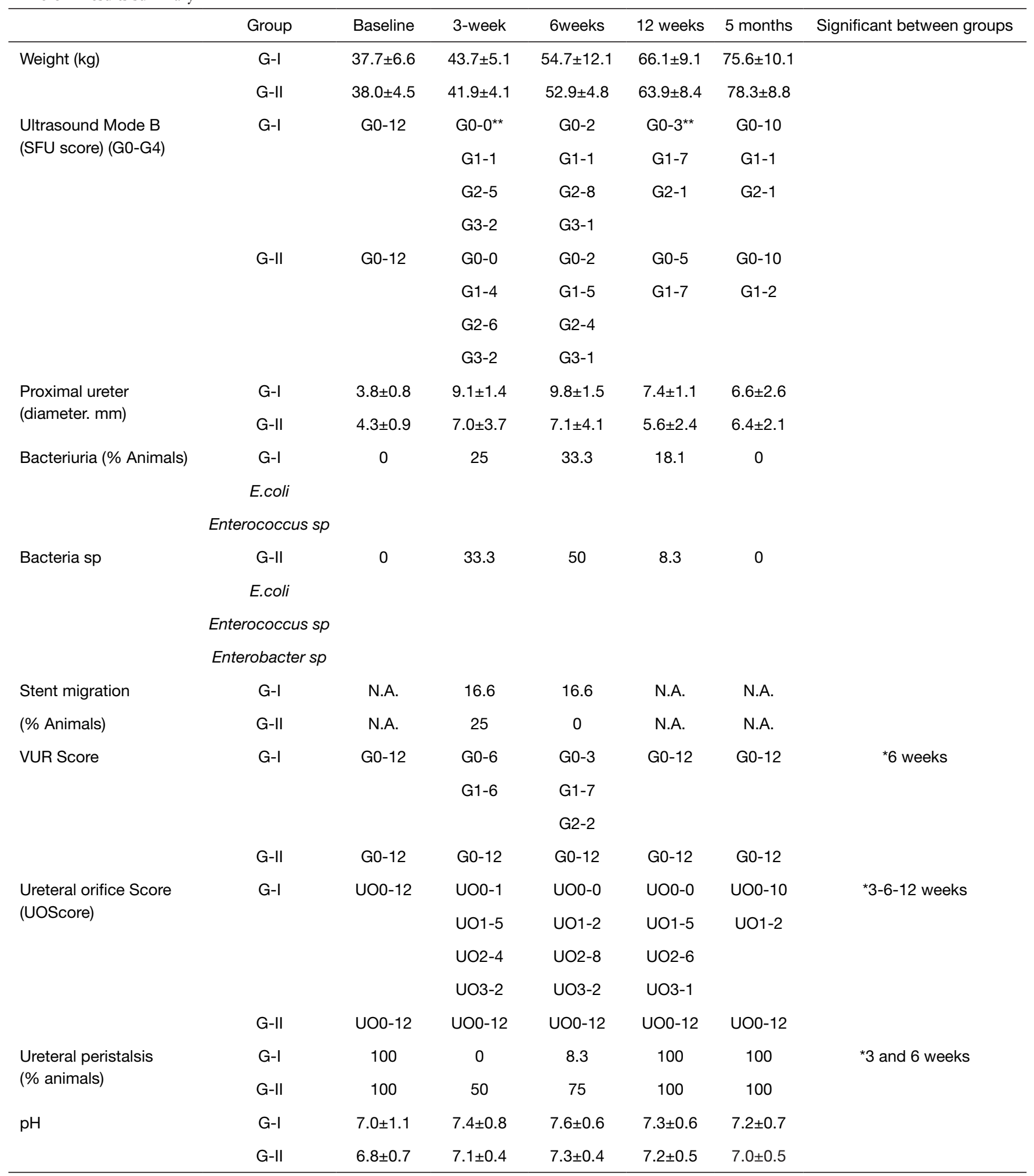

${ }^{*} \mathrm{P}<0.005 .{ }^{* \star}$ Missing dates. 
Table 2 Histological score

\begin{tabular}{|c|c|c|c|c|c|c|c|}
\hline $\begin{array}{l}\text { Group/ureteral } \\
\text { segment }\end{array}$ & $\begin{array}{l}\text { Urothelial } \\
\text { resurfacing }\end{array}$ & $\begin{array}{c}\text { Mural } \\
\text { inflammation }\end{array}$ & $\begin{array}{l}\text { Lamina propia } \\
\text { fibrosis }\end{array}$ & $\begin{array}{c}\text { Fibrosis } \\
\text { muscular } \\
\text { layer }\end{array}$ & $\begin{array}{c}\text { Integrity of } \\
\text { muscular } \\
\text { layer }\end{array}$ & $\begin{array}{c}\text { Serosal } \\
\text { alterations }\end{array}$ & $\begin{array}{l}\text { 0-3 Overall } \\
\text { Score }\end{array}$ \\
\hline Group-II- Endoureterotomy & 1.16 & 0.66 & 0.41 & 1.58 & 1.50 & 0.08 & $0.89 \pm 0.55$ \\
\hline Group-I-UVJ & $1.75^{\star \star}$ & $1.41^{* *}$ & $1.08^{\star *}$ & 1.08 & 0.83 & 0.16 & $1.05 \pm 0.49^{\ddagger}$ \\
\hline
\end{tabular}

${ }^{\star}$ Endoureterotomy site; ${ }^{*} \mathrm{UVJ}$; ${ }^{\dagger}$ Overall score endoureterotomy site and ${ }^{\ddagger}$ Overall Score-UVJ $(\mathrm{P}<0.05)$.

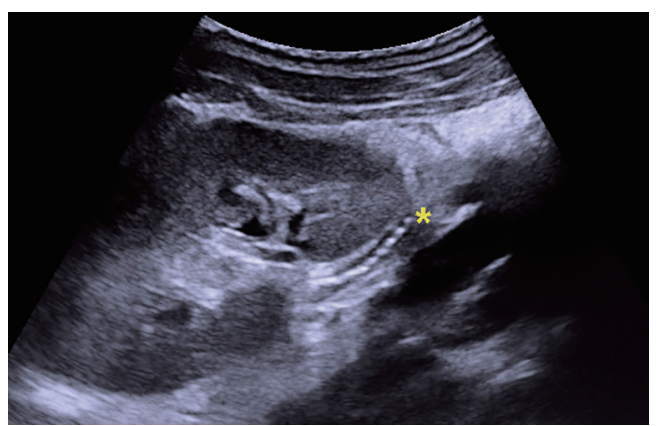

Figure 3 Stent assessment under ultrasound control (3 weeks). ${ }^{*}$ BraidStent ${ }^{\circledR}-\mathrm{H}$.

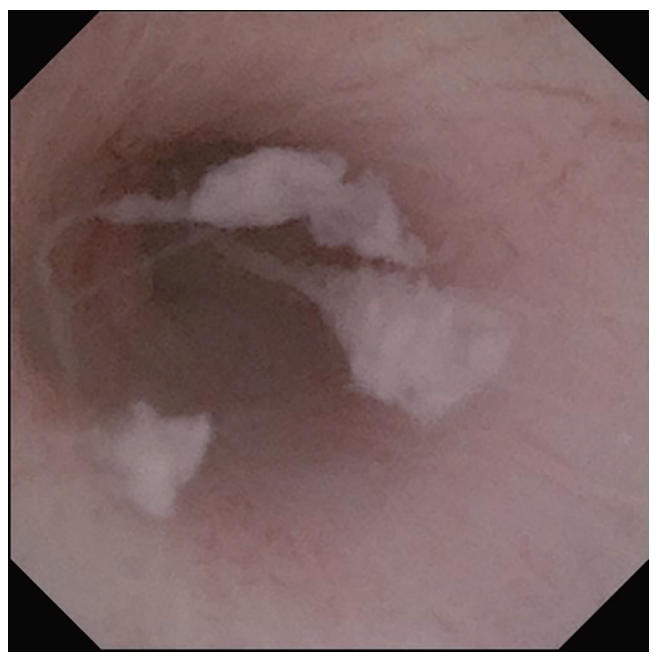

Figure 4 Ureteroscopic view of the non-obstructing BraidStent ${ }^{\circledR}$ $-\mathrm{H}$ fragments at 5 weeks.

\section{6-week follow-up}

The $91.7 \%$ of the BraidStent ${ }^{\circledR}-\mathrm{H}$ were completely degraded. Multiple small BUS hydrated fragments were

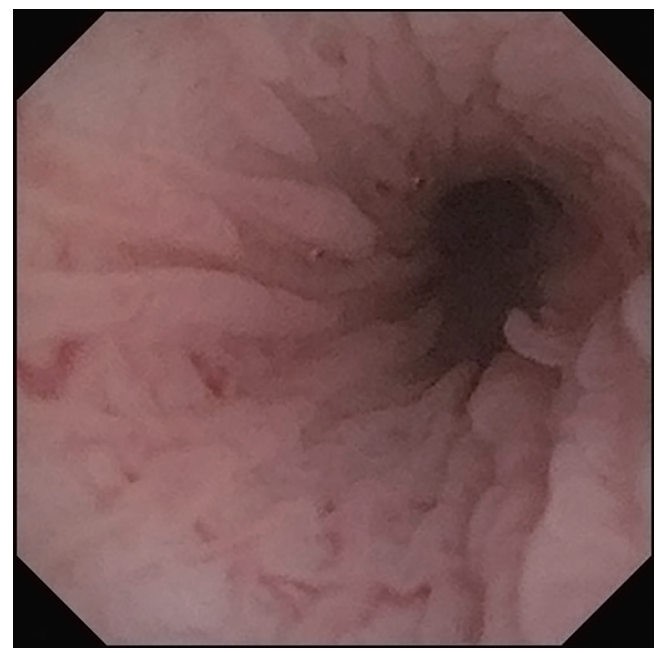

Figure 5 Non-obstructing urothelial hyperplasia. Distal anchoring system location.

found in the bladder; these could be easily aspirated through the ureteroscope working channel ( $<6$ Fr). Bacteriuria did not show any between-group significance, but GroupII revealed a worrisome $50 \%$ rate. Statistical significance was observed with respect to the percentage of animals with ureteral peristalsis, the urothelial damage assessed by cystoscopy at the ureteral orifice, and the VUR presence between groups, with worse results in Group-I. In GroupII, $75 \%$ of the animals showed distal ureteral peristalsis versus just $8.3 \%$ in Group-I. There was no longer evidence of urothelial hyperplastic reaction in the Group-II animals, which showed it at the previous follow-up (Figures 6 and 7).

\section{2-week follow-up}

There was no trace of the only BraidStent ${ }^{\circledR}-\mathrm{H}$ which had not degraded during the first six weeks. None of the study animals 


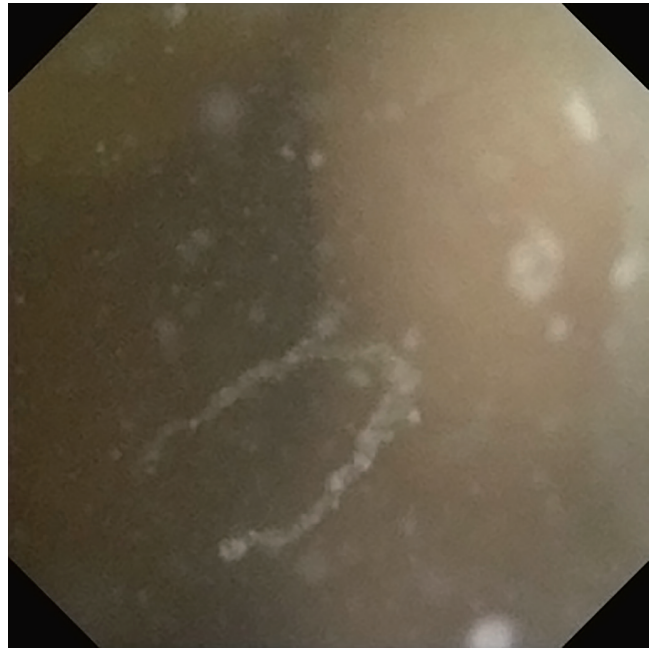

Figure 6 Cystoscopic view of the floating tiny non-obstructing BraidStent $^{\circledR}-\mathrm{H}$ fragments at 6 weeks.

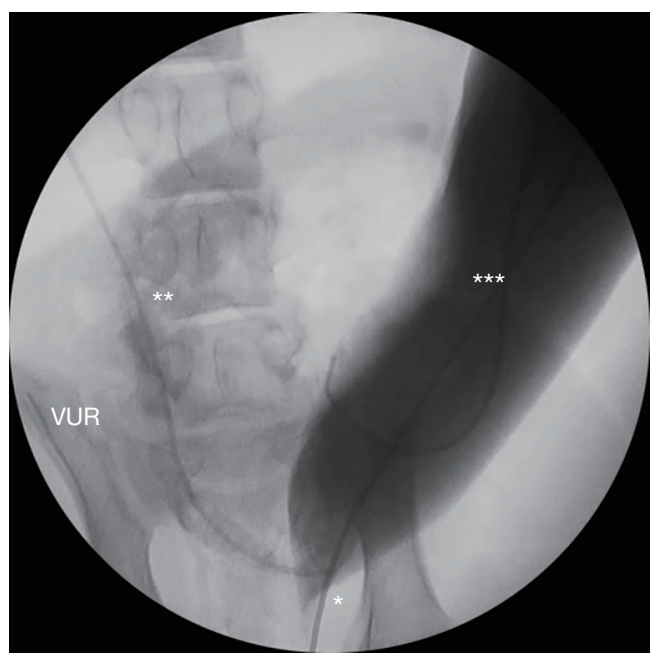

Figure 7 SVCUG. VUR Assessment in Group-I (6 weeks). ${ }^{*}$ Catheter to control intravesical pressure. ${ }^{* *}$ Double pigtail ureteral stent. ${ }^{* * *}$ Urine bladder.

showed VUR and all of them recovered ureteral peristalsis.

\section{Final follow-up}

Almost all parameters assessed during the study returned to their baseline values, except for the internal ureteral diameter in both groups. This was significant versus the baseline study, since the ureteral lumen was larger by the end of the study, as a consequence of the remodelling of

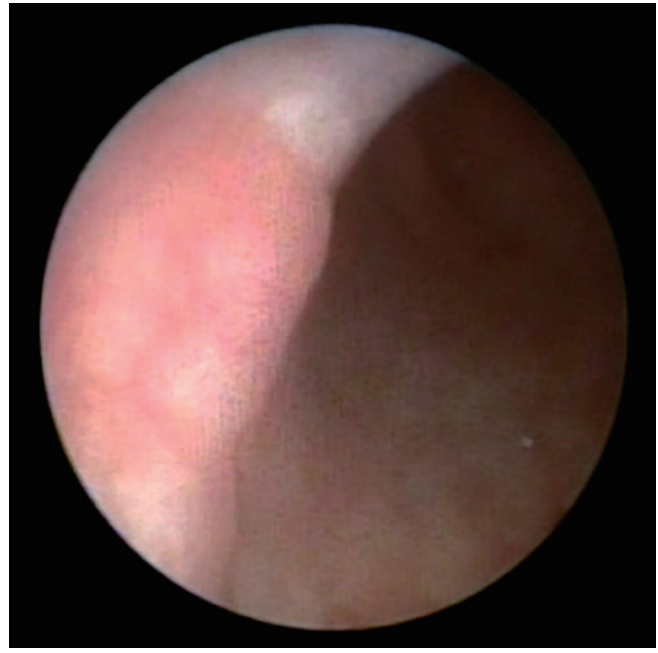

Figure 8 Ureteroscopic assessment of the ureteral healing in Group-II (5 months).

the ureteral wall caused by endoureterotomy and further stenting. However, it may also be due to the fact that the animals continue to grow and increase in weight throughout the study (Table 1, Figure 8). Retroperitoneal fibrosis was found during necropsy in 5 animals from each group at the endoureterotomy area, partially fixing the ureter to the psoas muscle. Among those 10 animals were the two which showed the small urine collection at 3 weeks. Both animals were considered as treatment failure at the end of the study. No significance was observed in the success rate in relation to the retroperitoneal fibrosis values; therefore, retroperitoneal fibrosis did not impact therapeutic success. Global success rate by groups was $91.6 \%$ and $87.5 \%$ in Groups-I and II, respectively, with no statistical significance.

The pathological study of ureteral wall at the endoureterotomy area showed between-group statistical significance in the "lamina propria fibrosis" and "serosal alterations" parameters. Significance was also found at UVJ/bladder trigone area for the "urothelial resurfacing", "mural inflammation" and "lamina propria fibrosis" study parameters. Finally, statistical significance was observed when comparing the "histological overall score" in both study domains, with moderate changes in Group-I and mild changes in Group-II. This corresponds to greater tissue damage and worse healing in Group-I. (Table 2).

\section{Discussion}

Treatment of US focuses on preservation of renal function 
and symptom control, as well as minimising morbidity (1). Laser endoureterotomy has been recommended in the last two decades as a first-choice technique for well-selected patients, mainly for benign ureteral stricture $<2 \mathrm{~cm}$ in length, non-ischemic, with brief stricture duration, proper renal function, and localized at the ureter ends $(1,4)$. The present success rate associated with laser endoureterotomy varies from $52.6 \%$ to $85 \%(15,16)$.

The use of ureteral stents after endoureterotomy is a constant in all clinical series $(15,16)$. Ureteral stents ensure adequate second-intention healing of the ureter after incision, reduce urinary extravasation, and allow urinary drainage of pyelocalyceal system $(17,18)$. However, current ureteral stents are associated with high morbidity and an important decrease in patients' quality of life (11). For this reason, BraidStent ${ }^{\circledR}-\mathrm{H}$ has been assessed in this study, as well as with the purpose of evaluating its use in the treatment of benign ureteral stricture. This stent stands out because it is a BUS with heparin coating to reduce bacterial adhesion and biofilm formation on its surface.

The comparative study has demonstrated that BraidStent ${ }^{\circledR}-\mathrm{H}$ is as efficacious as current ureteral stents to ensure well-sealed healing of the incised ureter. It did not show any differences in the ability to drain the pyelocalyceal system. It is important to highlight that due to the design of the BraidStent ${ }^{\circledR}-\mathrm{H}$, treatment of ureteral strictures in the two $\mathrm{cm}$ above the ureteral orifice are not indicated. Since it is an intraureteral stent to avoid VUR and stent material in the urinary bladder, it must always be $2 \mathrm{~cm}$ above the ureteral orifice. In addition, similar ureteral lumen dilatation at the endoureterotomy area was reached in both groups at 5 months. The BUS significantly reduced the side effects of current stents during the six stenting weeks, since it did not exhibit VUR or caused irritant effects in the bladder. BraidStent ${ }^{\circledR}-\mathrm{H}$ made it possible to preserve distal ureteral peristalsis in $50 \%$ to $75 \%$ of the animals at 3-6 weeks, respectively, with statistical significance, since it is designed to remain always strictly in the ureter, leaving some centimetres in the distal ureter free. Maintenance of ureteral peristalsis could be related to the improvement in patients' quality of life, because it has recently been demonstrated that the greatest nerve density in the human ureter is located distally (19). This finding, along with the fact that peristalsis can reduce ureteral spasm, directly related to acute pain episodes, and one of the causes for the use of alpha-blockers, which are also prescribed for LUTS treatment, could lead us to believe that the use of intraureteral stents which do not interfere with the distal ureter would avoid the need for alpha-blockers and antimuscarinics (20). Nevertheless, a series of clinical studies will be necessary to evaluate this hypothesis.

Two clinical studies on intraureteral stents have showed their ability to reduce pain, in comparison with conventional stents $(21,22)$. By contrast with BraidStent ${ }^{\circledR}-\mathrm{H}$, these stents impinge upon the UVJ since, as they are not biodegradable, they need a short vesical segment to be removed cystoscopically. BraidStent ${ }^{\circledR}-\mathrm{H}$ will probably have similar effects in patients, as it is strictly intraureteral and allows juxtavesical ureteral peristalsis. Furthermore, the blind pathological study between the two experimental groups showed that there was significantly better ureteral healing of endoureterotomy in Group-II. The reasons could explain this difference are mainly: the stenting time although both stents remain in place for 6 weeks, the BraidStent ${ }^{\circledR}-\mathrm{H}$ is undergoing continuous degradation, which is more evident during the fourth and sixth weeks, decreasing its effect on the incised ureteral wall compared to the standard ureteral stent. This should result in less friction with the ureteral wall, triggering less oedema and less compressive effect on ureteral second intention-healing area. Also, as the BraidStent ${ }^{\circledR}-\mathrm{H}$ does not show any VUR, this should favour ureteral healing, unlike the standard ureteral stent group. This corroborates the results of previous studies that supported that it is not necessary to intubate the entire length of the ureter to allow ureteral healing and proper drainage of the urinary tract $(8,13)$.

The fact that it is not necessary to remove BUS is not their only advantage; rather, they also avoid the "forgotten stent syndrome" and reduce medical costs associated with ureteral stents. Attempts have been made in recent years to obtain a BUS with clinical applications, but the first of these, unfortunately, showed problems with biocompatibility, degradation rate, and presence of obstructive fragments $(23,24)$. The most recent animal model studies have revealed a decrease in the appearance of obstructive fragments and adequate biocompatibility $(6,7,25)$. However, BUS still show poor control of degradation rate, because their degradation in the animal model is too fast or because they feature a wide degradation time interval $(6,7,25,26)$. BraidStent ${ }^{\circledR}-\mathrm{H}$ demonstrated a programmed and predictable degradation rate in this study; $91.7 \%$ of them completely degrade in the sixth week, for which it was designed. The BraidStent ${ }^{\circledR}-\mathrm{H}$ dwell time corresponds to the majority of recent clinical series following laser endoureterotomy (2,27-29). BUS degradation rate is mainly controlled by the selection of polymers and co-polymers. This will make it possible 
to elect stent degradation time in the future, depending on the combination of the biodegradable biomaterials selected. BraidStent ${ }^{\circledR}-\mathrm{H}$ also undergoes nonobstructive fragmentation. Firstly, this is due to the different polymers, and secondly, to its braided design: it is made of fine threads, whose gradual fragmentation produces tiny pieces which are excreted in the urine. This new design does not affect the success rate after US endoscopic treatment. The success rate is similar in the experimental groups compared, and compared with clinical series $(15,16)$. BraidStent ${ }^{\circledR}-\mathrm{H}$ is the only BUS that has been assessed against obstructive uropathy models, after these were treated with minimally invasive procedures $(8,13)$.

Despite these positive results, BraidStent ${ }^{\circledR}-\mathrm{H}$ yielded a disappointing asymptomatic bacteriuria rate. The use of heparin for ureteral stent coating to prevent bacterial adhesion and avoid biofilm formation has been described in detail in the scientific literature $(9,10)$. However, just as other researchers, we find that the heparin coating did not decrease bacterial adhesion (30). Covering BraidStent ${ }^{\circledR}$ with a heparin coating was intended to avoid the main source of the bacterial colonisation that occurs at the time of ureteral placement by the introduction of bacteria via the transurethral route into the urinary tract (31). The heparin coating was mainly released in the first 72 hours so as not to adversely affect the degradation rate, as our in vitro studies showed. This might have weakened the anti-adhesive effect. The high bacteriuria rate observed in the study may be due to the fact that the tiny degradation fragments drained with the urine carry the unavoidable biofilm associated with any biomaterial placement in contact with urine (31). This biofilm remains isolated and protected on the stent surface in a current ureteral stent, but in a BUS, at a certain point the stent surface fragments over weeks, and sweeps biofilm bits containing planktonic bacteria along. We found no differences between the bacteria identified in urine in both experimental groups (E. coli, Enterococcus sp, Enterobacter sp), compared to other studies in a swine model, nor between the most commonly identified bacteria associated with indwelling ureteral stents in patients (32-35).

The study shows some limitations related to VUR assessment and SVCUG use instead of voiding cystourethrography. Discomfort linked to stents cannot be assessed by USSQ, and it is also difficult to evaluate whether daily changes of $\mathrm{pH}$ in humans can modify the BraidStent ${ }^{\circledR}-\mathrm{H}$ degradation rate, as the animals follow a controlled diet. Although a long 5-month follow-up was carried out in the present study and various authors have confirmed that endoureterotomy treatment failure was uniformly evident within the first $1.6-3$ months $(28,29)$, other researchers extend the onset time of recurrences at 9-18 months $(4,16)$.

\section{Conclusions}

BraidStent ${ }^{\circledR}-\mathrm{H}$ has been shown to be as efficacious as current ureteral stents in the treatment of benign ureteral strictures following laser endoureterotomy. In addition, it reduces the morbidity associated with current stents and has a homogeneous and predictable degradation rate of about 6 weeks, with no obstructive fragments. Future studies are required to improve the antibacterial coating to reduce BraidStent ${ }^{\circledR}-\mathrm{H}$ contamination in view of the results obtained with the heparin coating.

\section{Acknowledgments}

The authors acknowledge to Ms. Fernanda Carrizosa for her generous support during the performance of this manuscript and Ms. Paula Martín Rodríguez and Ms. María Pérez Vela for the BraidStent ${ }^{\circledR}$ illustrations.

Funding: This research was funded by a grant from the Instituto de Salud Carlos III through the projects "PI13/02417" and "PI16/01707" (Co-funded by European Regional Development Fund "A way to make Europe").

\section{Footnote}

Reporting Checklist: The authors have completed the ARRIVE reporting checklist. Available at http://dx.doi. org/10.21037/tau-21-19

Peer Review File: Available at http://dx.doi.org/10.21037/ tau-21-19

Data Sharing Statement: Available at http://dx.doi. org/10.21037/tau-21-19

Conflicts of Interest: All authors have completed the ICMJE uniform disclosure form (available at http://dx.doi. org/10.21037/tau-21-19). Dr. Soria reports that he has a patent EP2749311 issued to JUMISC. Dr. Sanchez-Margallo reports that he has a patent EP2749311 issued to JUMISC. The other authors have no conflicts of interest to declare.

Ethical Statement: The authors are accountable for all 
aspects of the work in ensuring that questions related to the accuracy or integrity of any part of the work are appropriately investigated and resolved. Experiments were performed under a project license (NO.: 003/13) granted by Jesus Uson Minimally Invasive Surgery Centre's Ethical Committee for Animal Research, in compliance with The Institutional Animal Care and Use Committee European Union (Directive 2010/63/EU on the protection of animals used for scientific purposes).

Open Access Statement: This is an Open Access article distributed in accordance with the Creative Commons Attribution-NonCommercial-NoDerivs 4.0 International License (CC BY-NC-ND 4.0), which permits the noncommercial replication and distribution of the article with the strict proviso that no changes or edits are made and the original work is properly cited (including links to both the formal publication through the relevant DOI and the license). See: https://creativecommons.org/licenses/by-nc-nd/4.0/.

\section{References}

1. Kachrilas S, Bourdoumis A, Karaolides T, et al. Current status of minimally invasive endoscopic management of ureteric strictures. Ther Adv Urol 2013;5:354-65.

2. Emiliani E, Breda A. Laser endoureterotomy and endopyelotomy: an update World J Urol 2015;33:583-7.

3. Lucas JW, Ghiraldi E, Ellis J, et al. Endoscopic Management of Ureteral Strictures: an Update. Curr Urol Rep 2018;19:24.

4. Gnessin E, Yossepowitch O, Holland R, et al. Holmium laser endoureterotomy for benign ureteral stricture: a single center experience. J Urol 2009;182:2775-9.

5. Joshi HB, Stainthorpe A, MacDonagh RP, et al. Indwelling ureteral stents: evaluation of symptoms, quality of life and utility. J Urol 2003;169:1065-9.

6. Barros AA, Oliveira C, Ribeiro AJ, et al. In vivo assessment of a novel biodegradable ureteral stent. World J Urol 2018;36:277-83.

7. Jin L, Yao L, Zhou Y, et al. Investigation of a novel gradient degradable ureteral stent in a beagle dog model. J Biomater Appl 2018;33:466-73.

8. Soria F, de la Cruz JE, Budia A, Serrano A, et al. Experimental Assessment of New Generation of Ureteral Stents: Biodegradable and Antireflux Properties. J Endourol 2020;34:359-65.

9. Cauda F, Cauda V, Fiori C, et al. Heparin coating on ureteral double $\mathrm{J}$ stents prevents encrustations: an in vivo case study. J Endourol 2008;22:465-72.

10. Tenke P, Riedl CR, Gwennan Ll, et al. Bacterial biofilm formation in urologic devices and heparin coating as preventive strategy. Int J Antimicro Agents 2004;23S1:S67-S74.

11. Giannarini G, Keeley FX Jr, Valent F, et al. Predictors of morbidity in patients with indwelling ureteric stents: results of a prospective study using the validated ureteric stent symptoms questionnaire. BJU Int 2011;107:648-54.

12. Fernbach SK, Maizels M, Conway JJ. Ultrasound grading of hydronephrosis: introduction to the system used by the Society for Fetal Urology. Pediatr Radiol 1993;23:478-80.

13. Soria F, Morcillo E, Serrano A, et al. Evaluation of a new design of antireflux-biodegradable ureteral stent in animal model. Urology 2018;115:59-64.

14. Baer GM, Small W, Wilson TS, et al. Fabrication and in vitro deployment of a laser-activated shape memory polymer vascular stent. BioMed Eng OnLine 2007;6:43.

15. Corcoran AT, Smaldone MC, Ricchiuti DD, et al. Management of benign ureteral strictures in the endoscopic era. J Endourol 2009;23:1909-12.

16. Hibi H, Ohori T, Taki T, et al. Long-term results of endoureterotomy using a holmium laser. Int J Urol 2007;14:872-4.

17. Andreoni CR, Lin HK, Olweny E, et al. Comprehensive evaluation of ureteral healing after electrosurgical endopyelotomy in a porcine model: original report and review of the literature. J Urol 2004;171:859-69.

18. Rehman J, Ragab MM, Venkatesh R, et al. Smoothmuscle regeneration after electrosurgical endopyelotomy in a porcine model as confirmed by electron microscopy. J Endourol 2004;18:982-8.

19. Vernez SL, Okhunov Z, Wikenheise J, et al. Precise characterization and three-dimensional reconstruction of the autonomic nerve distribution of the human ureter. J Urol 2017;197:723-9.

20. Zhou L, Cai X, Li H, Wang KJ. Effects of $\alpha$-blockers, antimuscarinics, or combination therapy in relieving ureteral stent-related symptoms: A meta-analysis. J Endourol 2015;29:650-6.

21. Yoshida $T$, Inoue $T$, Taguchi $M$, et al. Efficacy and safety of complete intraureteral stent placement versus conventional stent placement in relieving ureteral stent related symptoms: A randomized, prospective, single blind, multicenter clinical trial. J Urol 2019;202:164-70.

22. Vogt B. A New Customized Ureteral Stent with nonrefluxing silicone end-piece to alleviate stent-related symptoms in malignant diseases. Urology 2020;137:45-9. 
23. Lingeman JE, Preminger GM, Berger Y, et al. Use of a temporary ureteral drainage stent after uncomplicated ureteroscopy: results from a phase II clinical trial. J Urol 2003;169:1682-8.

24. Hadaschik BA, Paterson RF, Fazli L, et al. Investigation of a novel degradable ureteral stent in a porcine model. J Urol 2008;180:1161-6.

25. Zhang MQ, Zou T, Huang YC, et al. Braided thin-walled biodegradable ureteral stent: preliminary evaluation in a canine model. Int J Urol 2014;21:401-7.

26. Wang L, Yang G, Xie H, Chen F. Prospects for the research and application of biodegradable ureteral stents: from bench to bedside. J Biomater Sci Polym Ed 2018;29:1657-66.

27. Lin CM, Tsai TH, Lin TC, et al. Holmium: yttriumaluminum-garnet laser endoureterotomy for benign ureteral strictures: a single-centre experience. Acta Chir Belg 2009;109:746-50.

28. Gdor Y, Gabr AH, Faerber GJ, et al. Success of laser endoureterotomy of ureteral strictures associated with ureteral stones is related to stone impaction. J Endourol 2008;22:2507-11.

29. Lane BR, Desai MM, Hegarty NJ, Streem SB. Long-term

Cite this article as: Soria F, de La Cruz JE, Fernandez T, Budia A, Serrano Á, Sanchez-Margallo FM. Heparin coating in biodegradable ureteral stents does not decrease bacterial colonization-assessment in ureteral stricture endourological treatment in animal model . Transl Androl Urol 2021;10(4):17001710. doi: $10.21037 /$ tau-21-19 efficacy of holmium laser endoureterotomy for benign ureteral strictures. Urology 2006;67:894-7.

30. Lange D, Elwood CN, Choi K, et al. Uropathogen interaction with the surface of urological stents using different surface properties. J Urol 2009;182:1194-200.

31. Zhang JM, Liu J, Wang K, et al. Observations of bacterial biofilm on ureteral stent and studies on the distribution of pathogenic bacteria and drug resistance. Urol Int 2018;101:320-6.

32. Soria F, Sánchez FM, Sun F, et al. Comparative study of ureteral stents following endoureterotomy in the porcine model: 3 vs 6 weeks and 7F vs 14F. Cardiovasc Intervent Radiol 2005;28:773-8.

33. Soria F, Delgado MI, Rioja LA, et al. Endourologic techniques for ureteropelvic junction obstruction therapy. Comparative animal study. J Pediatr Surg 2008;43:1528-32.

34. Al KF, Denstedt JD, Daisley BA, et al. Ureteral stent microbiota is associated with patient comorbidities but not antibiotic exposure. Cell Rep Med 2020;1:100094.

35. Kehinde EO, Rotimi VO, Al-Hunayan A, et al. Bacteriology of urinary tract infection associated with indwelling J ureteral stents. J Endourol 2004;18:891-6. 